\title{
Debate
}

CONTROVERSIES IN OPHTHALMOLOGY

\section{Predictive DNA testing in ophthalmology}

\section{Series editors: Susan Lightman and Peter McCluskey}

Correspondence to: Dr David A Mackey, Centre for Eye Research Australia, Royal Victorian Eye and Ear Hospital, 32 Gisborne Street, East Melbourne, 3002 ,

Australia:

D.Mackey@utas.edu.au

Accepted for publication 14 October 2002

\section{A Mackey, E Héon, A R Webster}

A 28 year old man with retinitis pigmentosa (RP) presents with his 4 year old daughter who is afraid of the dark and is bed wetting. He would like his daughter to have a DNA test to determine whether she has RP. The man was diagnosed with RP at age 7 years after his parents noted nyctalopia and he had a confirmatory electroretinogram (ERG). The man's father was diagnosed at age 30 years, while the man's younger sister was diagnosed at age 5 years. The man also has a son age 7 years, who seems to have normal vision. None of the adults with RP had visual fields good enough to hold a driver's licence. The pedigree is shown in Figure 1.

With many patients aware of the publication of the human gene map, clinicians are frequently asked about DNA testing. Could we organise the DNA test? Which genes could we test? Where could it be done? How much would it cost? How accurate are the results?

With any investigation we should ask "How will it change the management of the child?" Should we suggest using a night light or not? Are there any ethical concerns about doing the DNA test? Isn't it simpler to organise an ERG?

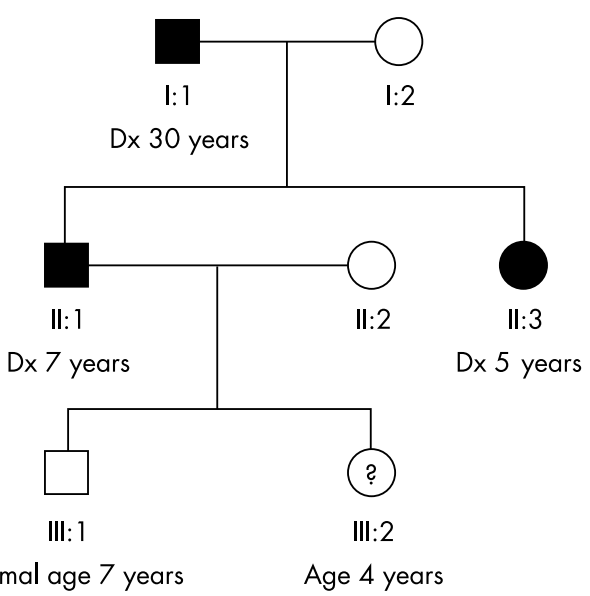

Figure 1 Pedigree showing affected members (solid symbols) and current age or age of diagnosis (Dx) of retinitis pigmentosa.

\section{Predictive DNA testing in ophthalmology: View 1}

\section{E Héon}

$\mathrm{T}$ his family appears to have an early onset autosomal dominant (AD) RP. There is male to male transmission, which excludes $X$ linked RP. ${ }^{1}$ Although the man's father was diagnosed at an older age this may be because the family was unaware of RP at that time. Once the family is aware of the condition and its presenting symptoms they may present earlier, as would appear to be the case with the girl in question. At age 4 years it is unlikely that there would be any abnormality detected on fundus examination.

\section{RP genes and mutations screening}

Department of Ophthalmology, University of Toronto, The Hospital for Sick Children and the University Health Network, Toronto, Ontario, M5T 2S8, Canada; eheon@uhnres.utoronto.ca
There are at least 13 genes that cause ADRP. These are listed in Table 1. An updated listing of retinal dystrophy genes is available on RetNet (http:// www.sph.uth.tmc.edu/Retnet/home.htm) and OMIM (http://www3.ncbi.nlm.nih.gov/Omim/ searchomim.html).

\section{Genetic analysis of RP}

Different approaches can be used to determine the genetic background of a disease depending on the type of samples available. When a family with several affected individuals is available, linkage analysis can be used to include or exclude gene loci of interest. Otherwise, for the more common scenario of sporadic cases, mutational analysis of candidate genes is used.

\section{Linkage analysis}

If several family members are available for testing and motivated, then a linkage analysis could be performed for the known loci. Definitely unaffected family members are also useful for this analysis. With just three affected members, it may not be possible to be certain which gene is involved, but it may be possible to exclude some loci. If there were a large number of affected individuals (that is, 10 people) and the analysis had excluded known loci, then it would be possible to do a genome-wide scan for the identification of a 


\section{Debate}

new RP locus. I would prioritise the gene loci associated with early onset RP and ADRP. Even though there was one family member with a late diagnosis, as clinically this sounds like an early onset disease.

\section{Mutation screening}

Although it would be possible to screen each of the genes for mutations, this would be a large undertaking and the resources are usually not there to do it completely. In this case only a few candidate genes such as rhodopsin and RDS would be looked at. Determining the genetic background of the disease is important to better understand its progression. However, the great genetic heterogeneity of RP had not been anticipated and most centres do not have the infrastructure to provide molecular analysis of all the known RP genes.

\section{Availability and cost of DNA testing: this is the million dollar question!}

Where to get the testing done depends on where you are and who you collaborate with. When you send samples from the same family to different laboratories it is important that this is discussed a priori. This can be a very frustrating scenario and can lead to potential conflicts as these tests are usually still done on a research basis and are very time consuming.

Who pays? Very few health systems are willing to pay for DNA testing. Some laboratories have limited funds for semi-research DNA testing. I don't think at this point that the quality of the diagnosis we offer warrants billing patients directly. By this I mean that the genetic characterisation of the disease is incomplete. In many cases we will not find the gene mutation involved and at present we cannot give patients a full interpretation of the results.

\section{How do you know a base change is a mutation and is disease causing?}

Distinguishing between disease causing mutations and benign polymorphisms in RP (or any disease) genes can be quite difficult. Just because a mutation has been reported in the literature doesn't prove it is pathogenic and that is where having a family to study becomes useful. A family allows the assessment of the segregation of the defect to be identified and the determination of whether it segregates with the disease status or not. This family definitely would allow assessment of segregation for the sequence change with the disease phenotype. Ethnically matched normal population controls should also be tested.

In this case that should do it.

\section{How we could change management?}

Definitely attempt an ERG although she is age 4 years. At 7 years you can try a Goldmann visual field examination. Examining other affected family members would allow a better understanding of the phenotype in this family. I am not against early diagnosis as it provides longitudinal information that can be useful in future management opportunities.

A night light is certainly worth a try but is also psychological support to the child. It's not a treatment it's a tool. I usually tell the children, parents, and whoever else is involved that they should always have a pocket flashlight. It can be very handy. They can keep it by their pillow or on their night table and it usually brings reassurance in the dark. Do night lights cause myopia? This is a controversial area, ${ }^{23}$ although I wouldn't worry about it personally. This is a separate issue from the RP and I think the RP management is more important.

\section{Predictive DNA testing}

It all depends why the family wants to do it. I often use electrophysiology testing more than molecular testing in this type of case, unlike DNA testing in glaucoma. The main issues in adults relate to insurance; however, in children issues are more complex.

Issues in children include fear of the child and of parents. However, this could also turn into good guidance. Molecular testing provides evidence for a risk factor, the diagnosis remains clinical.

\section{ERG compared with DNA testing}

The reliability and predictiveness of the tests differ and it depends at what age it is done. In the case of ERG, performing it too early can lead to a false negative, whereas in the case of molecular testing a gene with incomplete penetrance can yield a false positive. In other words, a gene mutation reflects a risk factor for the development of the disease but it does not imply that the patient will definitely develop the disease. Further research is needed to clarify the penetrance

Table 1 Retinitis pigmentosa, autosomal dominant

\begin{tabular}{|c|c|c|c|}
\hline \multirow[b]{2}{*}{ Genes identified } & \multicolumn{2}{|c|}{ Gene linked } & \\
\hline & RP17 & $17 q 22$ & \\
\hline $\begin{array}{l}\text { CRX } \\
\text { FSCN2 }\end{array}$ & CORD2 & $\begin{array}{l}19 q 13.3 \\
17 q 25\end{array}$ & $\begin{array}{l}\text { cone-rod otx-like photoreceptor homeobox transcription factor } \\
\text { retinal fascin }\end{array}$ \\
\hline HPRP3 & RP18 & $1 q 21.1$ & human homologue of yeast pre-mRNA splicing factor 3 \\
\hline IMPDH] & RP10 & $7 q 31.1$ & inosine monophosphate dehydrogenase 1 \\
\hline$N R L$ & RP27 & $14 q 11.2$ & neural retina lucine zipper \\
\hline PRPC8 & RP13 & $17 p 13.3$ & human homologue of yeast pre-mRNA splicing factor $\mathrm{C} 8$ \\
\hline PRPF31 & RPI 1 & $19 q 13.4$ & human homologue of yeast pre-mRNA splicing factor 31 \\
\hline RDS & RP7 & $6 p 21.2$-cen & peripherin/RDS \\
\hline $\mathrm{RHO}$ & RP4 & $3 q 21-q 24$ & rhodopsin \\
\hline ROMI & & $11 q 13$ & retinal outer segment membrane protein 1 \\
\hline$R P 1$ & RPl & $8 q 11-q 13$ & $\mathrm{RP} 1$ protein \\
\hline RPQ & RPQ & $7 p 15.1-p 13$ & Pim-1 oncogene kinase \\
\hline
\end{tabular}


and expressivity of the different mutations. You need to explain both sides to the family. Usually I determine the age at which we do the ERG based on the age of onset of the symptoms and the family history. In this case I would definitely do an ERG.

Some ethicists say it is unethical to do DNA testing but do not raise the issue of doing an ERG

I disagree, it depends what you want to know, the expectations of the family, and the context and the disease. You need to tailor your approach, this is not one stop shopping! No one solution will be good for all patients and families. The key is to discuss all the issues with the family and to get their opinions on the "ethical issues." The first things I try to clarify is what they understand about the disease and their fears, then "what do they think of the status of the unaffected person?" What does knowing otherwise involve? I always make sure there is another person from our team present as a witness and document what was said, as misinterpretations are common especially when there is fear. I think the key here is guidance by the treating doctor in relation to implications and resources.

\section{REFERENCES \\ 1 Bird AC, Heckenlively JR, eds. Autosomal dominant retinitis pigmentosa. Ch 8:125-49, and $X$ linked recessive reitinitis pigmentosa, $\mathrm{Ch}$ 10:162-75. In: Retinitis pigmentosa. Philadelphia: JB Lippincott Co, 1988. \\ 2 Appen RE, Mares-Perlman J. Are the sky and night lights falling? Arch Ophthalmol 2000;1 18:701-2 \\ 3 Zadnik K. Association between night lights and myopia: true blue or a red herring? Arch Ophthalmol $2001 ; 119: 146$ \\ 4 McCabe LL, McCabe ER. Postgenomic medicine. Presymptomatic testing for prediction and prevention. Clin Perinatol 2001;28:425-34.}

Debate

(1)

Br J Ophthalmol 2003;87:635-636

\section{Predictive DNA testing in ophthalmology: View 2}

\section{A R Webster}

f

would counsel strongly against a "genetic test" for this young girl, even if there were a sensitive and specific genetic test available to determine the genetic status of an individual from this family. I would similarly argue that it would be wrong to perform such a test even if there were a sensitive and specific genetic test available to determine the genetic status of an individual from this family. The problem we face in managing this family is how best to present this view to parents who, as is not unusual, have already decided that a DNA test is exactly what their daughter needs.

\section{Laboratory testing considerations}

Let's imagine for a moment that we have the technology and detective skills to offer genetic testing for this girl. A positive result means she has a $100 \%$ chance of carrying the gene causative for RP in the family, and a negative result that there is a $100 \%$ chance that she has escaped inheriting the gene causative for RP in this family. This is rarely the case given the vast genetic heterogeneity of this disease. How might this unusual state of affairs have arisen? Well, we might have found that the family is segregating a missense mutation in the rod opsin gene, which would be the first gene investigated in a laboratory for the very reason that it is the most common cause of autosomal dominant RP. ${ }^{1}$ Rarely are we able to determine the mode of inheritance in a patient presenting with RP, but in this family, given the male to male transmission and three affected individuals, autosomal dominant (AD) RP seems to be on the cards. So, we have previously approached the family members, both affected and unaffected, expounding on the great future benefits of molecular research into these conditions, though we do admit that there are none yet. After such persuasion, most of the members gladly consent to entering our research and donate their DNA.

So what might happen in the laboratory? Let's fantasise for a moment and imagine we have at our disposal a laboratory with limitless molecular technology and a large number of well motivated laboratory technicians. The chief technician notes that ADRP is suspected; he considers the lab's strategy for ADRP and finds that screening for small mutations in the gene for rhodopsin is the first thing to do. He sets to work amplifying DNA with the polymerase chain reaction (PCR) from an affected member of the family for the five coding fragments of the gene (a gene of modest size consisting of only five exons). There are many methods that one can use to detect mutations in such fragments of DNA but, in this case, the technician prepares the high throughput wave denaturing high performance liquid chromatography machine (DHPLC for short) and analyses the products from the affected patient. One of these appears to show an abnormal pattern, suggesting a base change. He then determines the exact DNA sequence from this fragment on one of the $\mathrm{ABI}$ 3700 semiautomated sequencers at his disposal. Notice how many machines with large names this technician is depending on; molecular testing is indeed an expensive process. On looking at the sequence with some expensive computer software, he discovers not one, but two, DNA changes in the affected person's DNA sequence.
A R Webster Moorfields Eye Hospital, University Lecturer, Institute of Ophthalmology, Bath Street, London ECIV 9EL, UK: andrew.webster@ucl.ac.uk 
Debate

A change in a DNA sequence from the population "norm" does not necessarily indicate one that might cause disease. So he consults his online virtual library. He notices that both changes have been reported in the literature before. He then sequences the same PCR product from the other two affected members, an unaffected spouse and a couple of unaffected individuals from the family who were happy to donate DNA for the research. One of the two changes is only found in the first person analysed and his unaffected mother. That's important. The sequence change does not segregate with the disease and so cannot be the change that causes the disease in the family. Instead, it's one of those annoyingly common polymorphisms that happen in the population from time to time just to confuse geneticists and clinicians. He then prepares to write a short report to the BJO on how this previously considered disease-causing change exists on a non-segregating chromosome and is therefore a polymorphism. Less interesting from his point of view is the fact that the second change is found in the three affected individuals, not found in either of the two unaffected individuals, and not found in the spouse. It seems to segregate perfectly with the affected members of the family. Is that proof that it causes the disease? He taps out an approximate calculation on his computer and finds the odds of such a distribution in the family being due to true linkage with the disease compared to a chance finding is 16 to 1 . So, that's good odds that rhodopsin, at least, is responsible for this family's disease. But what about that specific change? He consults the literature again to find that the exact same base change has been described in at least four families with ADRP and not detected in at least 400 control chromosomes. Job done! The cause of the disease in this family has been determined. He doesn't even need to use the mutiplexed marker panel for other less common ADRP genes (further expense and usage of machines with long names). He reports back to the clinicians that should the change be confirmed in a diagnostic laboratory (remember we're in a research lab at the moment) on a second blood sample from an affected family member, then it should be possible to offer a sensitive and specific presymptomatic test on members of the family.

\section{Clinical considerations}

So, we go back to the clinic. The point of that preceding section was to demonstrate that molecular testing, particularly in a disease such as RP, is expensive, time consuming, and often imperfectly sensitive and specific. But, in order to consider ethical issues in this family's case, it is simpler to consider a test that can be offered with $100 \%$ sensitivity (no false negatives) and specificity (no false positives). Many ophthalmologists enjoy the fact that we work within an ethically straightforward specialty, but that is not always true, particularly when inherited disease is concerned. ${ }^{2}$ So now we can offer a robust test to this young girl. But should we? Let's assume that we do and that she tests positive. Her parents hear of the result the next month (there's an efficient diagnostic laboratory in town too!). They are sad that she has a genetic, potentially blinding disorder, passed down from her father, for which there is no treatment and no means of prevention. In the meantime, they move house, she has a different bedroom which she likes and she's no longer afraid of the dark. She no longer requires nappies at night as she has no further wetting of the bed. She goes through school, gets on well, and prepares for her GCSE examinations. At the age of 16, she becomes more aware of her father's deteriorating eye condition. This is important to her at this stage in that she is having to consider various career options and wonders whether she too may have a similar problem to her father. She learns that her great uncle also has the disease, and that is was only noticed on having his cataract surgery at the age of 75 years. The great uncle had a genetic test. It is positive. The doctors say that it is not at all unusual for there to be so much variation in RP even between the same members of a family. In fact, the few other families in the world with the same DNA change in rhodopsin have varied greatly in the severity of their disease (other rhodopsin changes are less variable). She discusses the issue with her parents and mentions that, as there's still no treatment, she would rather not know whether she has the gene for the disorder until there is a treatment. "Oh we already know you have the mistake in your genes, my dear," says mum. "We got you tested when you were four."

So the basic point is this. The young girl should be investigated for her symptoms. If there is a real suspicion of visual dysfunction, then her acuity should be assessed carefully, she should undergo a refraction and have her eyes examined. She should be treated like any other child presenting to the clinic. If the night blindness is real and disabling (which I doubt), then she could have an electroretinogram, looking for a reduction in amplitude in the Ganzfeld responses. It may be normal, which would be reassuring, but when performed at the age of 4 years would not rule out her later developing RP. If there is the possibility of a presymptomatic DNA test for an untreatable disorder then the patient herself should enter into the decision making when she is old enough to do so. Whose DNA are we testing here?

However, if a preventive treatment were known or even suspected, then that's a different scenario. We are currently doing predictive DNA testing in retinoblastoma. ${ }^{3}$ The patient herself would stand to gain from having such treatment before the onset of symptoms. She might even avoid the condition altogether despite her imperfect genome. But we're not at that stage yet, are we? Maybe one day we will be. Then this dilemma will not exist. We will encourage the parents to consent to their child having a presymptomatic test. We might even save her sight.

\section{REFERENCES}

1 Inglehearn CF, Tartelin EE, Plant C, et al. A linkage survey of twenty dominant retinitis pigmentosa families; frequencies of the nine known loci and evidence for further heterogeneity. J Med Genet 1998;35:1-5.

2 Clarke MP. There are ethical issues in ophthalmology. BM 1999;318:1153

3 Noorani HZ, Khan HN, Gallie BL, et al. Cost comparison of molecular versus conventional screening of relatives at risk for retinoblastoma. Am J Hum Genet 1996;59:301-7. 


\section{Debate Overview}

\section{A Mackey}

T wo clinical ophthalmic geneticists, who also have extensive laboratory experience, have provided opinions on the problems of predictive DNA testing in an ophthalmic setting of ADRP. The rapid progress of genetic research associated with the human genome project has raised many new ethical issues and made clinicians reconsider conventional treatment issues. Many ethical guidelines are being imposed on researchers and clinicians that will need to be modified in the future to reflect the changing perspective of the current clinical practice and in accordance with patient's wishes.

\section{How will it change management? Predictive DNA testing for an untreatable disease} A well informed adult can consent to a predictive DNA test. However, predictive DNA testing in children raises issues of what the child (as the person now and the adult he/she will become) would want. To only order an investigation that will change management is an important axiom of clinical care, not just for hospital financial administrators. Some would argue that there is no value in early diagnosis of RP as it will not change management. This applies to the electrophysiology testing as much as the DNA testing. It is also important to consider the specificity and sensitivity of the ERG and the DNA test. The arguments for DNA testing if there was no other treatment and no risk of using a night light would be poor. However, there is a slight chance that treatment for nyctalopia with a night light may not be totally safe. This is a controversial area. Most studies conducted since the original paper proposing that night lights cause myopia have failed to support this finding. ${ }^{1}$ If the parents were insistent despite counselling, then the night light argument could be used to convince an ethics committee. Managing the RP is probably more important than managing myopia.

\section{How will it change management? Predictive DNA testing for a treatable disease}

Few people would argue against predictive DNA testing for a treatable disease such as retinoblastoma, where a negative DNA test can spare a child from 10 examinations under anaesthesia. ${ }^{2}$ Similarly in glaucoma (myocilin related) DNA testing allows early diagnosis and treatment to prevent glaucoma blindness. ${ }^{3}$ However, the timing of such testing would be an issue if the disease did not need to be treated until adulthood anyway. When will predictive DNA testing for RP be of value? How far away are treatments? The only tested preventive treatment for RP is high dose vitamin A. ${ }^{4}$ This in itself would be a topic for this series in the $B J O$. What if only some genetic subgroups of $\mathrm{RP}$ were responsive to high dose vitamin $\mathrm{A}^{5}$ (such as in the case of Sorby's fundus dystrophy ${ }^{6}$ ). Who would pay and organise the massive amount of
DNA testing to work out which genetic subgroup of RP each patient belonged to and how long it would take to screen everyone with RP? Research groups do not have the resources for this and may not still be set up to do testing on a gene that was studied over a decade ago. If the family knows which gene mutation they have then they may be proactive in seeking out new treatments. Few RP clinics would be able to contact all their patients if new treatments did become available. It is possible in this case scenario that the family could have their gene mutation identified now and the girl could be tested at a later date if deemed appropriate.

There is surprisingly little information on the sensitivity and specificity of the ERG, when one considers that this test has been in use for decades. The evaluation of the sensitivity and specificity of DNA testing is only in its very early stages. This will be an important area of future research. The worst case scenarios would be to tell someone they would get a severe disease when they will never be affected even though they carry a presumed mutation or to tell someone that they would not be affected when they do develop the condition.

\section{Genetic information resources}

Useful information is available on "Understanding gene testing" by the US Departments of Health and Human Services (http:// www.accessexcellence.org/AE/AEPC/NIH/ index.html).

Retina and retinitis pigmentosa organisations also have useful web pages. With the rapid changes in genetics it is useful to keep up to date with online resources. Lists of RP genes are available from Retnet (http://www.sph.uth.tmc.edu/ Retnet/home.htm) and OMIM (http://www3. ncbi.nlm.nih.gov/Omim/searchomim.html).

Proving that a particular gene is pathogenic is a more complex problem. Although many mutations are cited in the literature, many of these have been single case reports. It is likely that some of these will be polymorphisms rather than disease-causing mutations. Thus, incorrect predictive data could be given to a patient who is carrying a polymorphism.

If RP gene testing is requested by the family then the clinician should contact his/her local laboratory and genetics unit that may already have arrangements with a DNA testing laboratory. Contacting various research institutions around the world may identify a laboratory willing to do the DNA testing. An online listing of laboratories doing research or diagnostic testing is available from the University of Washington and Children's Health System, Seattle (http:// www.genetests.org). However, as the research phase of identifying RP DNA mutations is almost over, very few laboratories will offer this service 
Debate

free of charge. Families who were involved in earlier research studies now have access to the mutation present in their family and thus a cost effective test for other family members would be possible. For families who did not participate in earlier research, this is not possible without considerable expense.

\section{Where are my results?}

Many patients expect DNA results to be returned with the speed of a routine blood count. We must all give patients realistic time lines for preliminary and final results from DNA testing. Hopefully health funding bodies will see the benefit of funding DNA screening in an efficient manner. This may involve targeting common mutations in specific populations. Although we may be unable to provide $100 \%$ mutation screening, it may be efficient to just look for common mutations. In addition, there will be better information on the phenotype-genotype correlations of these as well as information on penetrance, age of onset, and expected visual outcome. Screening large families may cause problems with some members not wishing to participate and privacy concerns will need to be addressed.

\section{Considering the child's wishes}

If parents do have their children tested for genetic diseases, this is like many choices that parents make on behalf of their children. There is no right or wrong answer, but parents need to be made aware of issues and the possibility that the child may later wish to have had a different choice. One needs to look at the issue in a similar light to the disclosure of adoption to adopted children, where cultural norms have changed over the years. It may be better to inform children when they are younger than to have a genetic test result come as an agonising decision in later life. Does our current idea of forcing people to make choices all the time actually cause more harm than the century old method of letting the doctor decide? It may be less harmful to let a 4 year old know that she won't join the airforce than telling a 19 year old with her heart set on it. It is important to consider the time and place as well as the social and cultural setting of each family. The approach used for one may not be the same for another.

When parents have an ill child they would like everything possible to be done for their child. If no treatment is available then participating in research can be therapeutic for the family (just as setting up a charity or fund raising can be). It is important that we never take away hope from families with hereditary eye diseases by saying we can do nothing.

\section{Conclusion}

Genetic testing is just another enabling part of clinical medicine that should be funded as such. Although specific guidelines are imposed on genetic testing these should be the same for any clinical test "Will it change management?" and "What would the patient want?"

\section{ACKNOWLEDGEMENT}

This was supported by the Eye Ear Nose Throat Research Institute.

We would like to thank Lori Bonertz, Robert Buttery, Jamie Craig, Chris Inglehearn, Danielle Healey, and Lisa Kearns for their helpful comments on the manuscript.

\section{REFERENCES}

1 Quinn GE, Shin CH, Maguire MG, et al. Myopia and ambient lighting at night. Nature 1999;399:113-4.

2 Noorani HZ, Khan HN, Gallie BL, et al. Cost comparison of molecular versus conventional screening of relatives at risk for retinoblastoma. Am J Hum Genet 1996;59:301-7.

3 Parrish RK 2nd. When does information become medically useful?: the role of genetic testing in glaucoma Arch Ophthalmol 2002;120:1204-5.

4 Berson EL, Rosner B, Sandberg MA et al. A randomized trial of vitamin $A$ and vitamin $E$ supplementation for retinitis pigmentosa. Arch Ophthalmol 1993;111:761-72.

5 Li M, Sandberg MA, Pawlyk BS, et al. Effect of vitamin A supplementation on rhodopsin mutants threonine-17 $\rightarrow$ methionine and proline-347 $\rightarrow$ serine in transgenic mice in cell culture. Proc Natl Acad Sci USA 1998;95: $11933-8$

6 Jacobson SG, Cideciyan AV, Regunath G, et al. Night blindness in Sorsby's fundus dystrophy reversed by vitamin A. Nat Genet 1995;11:27-32. 